\title{
Comparative Study of Seismic Behavior between Monolithic Precast Concrete Structure and Cast-in-Place Structure
}

\author{
Chao-gang Qin $\mathbb{D}^{1},{ }^{1}$ Guo-liang Bai $\mathbb{D}^{,},{ }^{1}$ Ya-zhou Xu $\mathbb{D},{ }^{1}$ Ning-fen $S u,{ }^{1}$ and Tao $W u^{2}$ \\ ${ }^{1}$ School of Civil Engineering, Xian University of Architecture and Technology, Shaanxi 710055, China \\ ${ }^{2}$ School of Civil Engineering, Chang'an University, Shaanxi 710061, China \\ Correspondence should be addressed to Guo-liang Bai; guoliangbai@126.com
}

Received 15 June 2017; Accepted 16 August 2017; Published 2 January 2018

Academic Editor: Stefano Sorace

Copyright (C) 2018 Chao-gang Qin et al. This is an open access article distributed under the Creative Commons Attribution License, which permits unrestricted use, distribution, and reproduction in any medium, provided the original work is properly cited.

\begin{abstract}
We doubt whether the monolithic precast concrete structure could be designed as the cast-in-place structure in high seismic intensity area. To solve the puzzle, the $1 / 5$ scaled monolithic precast concrete structure model and cast-in-place structure model were designed and tested by shake table. Comparative analysis between them was made to better understand their seismic behavior. Based on the experimental results, the failure pattern and mechanism were different, which was concentrated damage in coupling beam and then extended to shear walls of CIPS, and the weak connections presented cracks between precast elements besides the damage coupling beam of MPCS. The natural frequency of MPCS possessed a typical feature for the weakness of connections, which was the initial one greater than that of CIPS and decreased fast after the first waves with PGA of $0.035 \mathrm{~g}$. Acceleration amplifying factors presented variation trend under the different earthquake waves. The distribution of seismic response presented linearity along the height of models in plastic stage and turned into nonlinearity later for severe damage. In general, the MPCS and CIPS had similar seismic responses, except typical characteristics. And they were proven to have better seismic performance without collapse under the high-intensity earthquake waves.
\end{abstract}

\section{Introduction}

Precast concrete structure is constructed with prefabricated elements made in factory, which is popularly used for residential buildings, industrial buildings, and public buildings, such as apartment, parking, and stadium. It possesses the high-quality precast elements: the speed of erection and freedom in the architectural shape of the members. However, the integrity and security of connections between the precast units are significant for global structure, especially under the earthquake excitations. As is well known, shear wall structure is an effective lateral resisting system for high-rise residential buildings $[1,2]$ in earthquake protection region.

The shear wall precast elements along story height are connected to form the lateral resisting system. In order to keep the validity of the horizontal connection, various ways are taken to connect the longitudinal reinforcements, such as grouted sleeve, posttensioning, and splice sleeves [3-7]. Further, the isolated shear walls with different horizontal connections were tested considering the contact surface and the mentioned connection of longitudinal rebar [810]. Vertical connection located between the story precast elements was investigated by Vaghei et al. [11]. Nowadays, the improved grouted sleeve is an effective connection of longitudinal reinforcements, and a monolithic vertical connection between the story precast elements is conducted to enhance their integrality. Namely, the vertical connection is the edge components of shear wall of cast-in-place structure.

The properties of prevalent connections of precast elements and the overall structure were conducted with pseudostatic test and pseudodynamic test [12-15], whereas the tests did not consider the influence of the duration of earthquake waves. One kind of precast wall structure large-panel precast concrete building of three single-bay simple walls was tested by Oliva et al. [16] and a 3-story model structure was tested by Lee et al. [17]. And the seismic properties of a 1/4 scaled precast structure with high damping rubber bearings were studied by Wang et al. [18]. Nevertheless, some research reports detected that precast structure was not with excellent seismic behavior during the previous earthquake for failures 
of welded and poorly constructed connections $[19,20]$. Further experimental research is clearly needed to fill the gap in the knowledge of seismic behavior of precast concrete structure. And large-scale shake table test is a reliable method to research the dynamic seismic response of precast concrete structure.

This paper presents a comparative shaking table test program realized on two 1:5 scaled models of a 12-story shear wall structure to understand the dynamic seismic response of precast concrete structure. One is cast-in-place structure (CIPS), and the other is monolithic precast concrete structure (MPCS). The prototype structure was designed in two bays and two spans in accordance with the provisions of code [21], and the splitting design of MPCS was according to the code [22] and design drawings sheets [23]. Based on the testing results, the dynamic characteristics of the two models, such as frequency, damping ratio, and mode shape, are evaluated through the white-noise test. In comparison, the failure pattern and mechanism, seismic force response, story shear, story displacement, and interstory drift will be intensively explored, analyzed, and discussed. Finally, the comprehensive understanding of seismic performance of MPCS and CIPS will be revealed, especially the earthquake response of the MPCS in its entirety.

\section{Experimental Program}

\subsection{Model Design}

2.1.1. Similitude Relationship. As the performance parameters of shake table and condition of lift in laboratory, scaled model was applied in shake table test. Prototype structure was designed observing the provisions of Chinese code [21]. And the reduced scale design for the models was established from Buckingham's Pi theorem [24]. The similar constants of geometry, stress, and acceleration were first defined as 0.2 , 0.2 , and 1 , respectively [25]. And then the other parameters were deduced by the similitude rules and summarized in Table 1. The CIPS and MPCS had the same similitude rules. Furthermore, the models were designed as elastic-plastic models to observe the plastic behavior under the highintensity earthquake waves [26].

2.1.2. Material Design. As the scaled parameters of physics, the stress and elastic modulus of the model material decreased to $20 \%$ of that of the concrete of prototype structure. The microconcrete was adopted as model material for the limitation of coarse aggregate. Shen et al. proposed ceramsite, powder coal ash, or pumice as blending agent could reduce the elastic modulus of microconcrete [27]. So the gypsum was mixed to the microconcrete. After testing, the model material was a compound with cement: fine aggregate: coarse aggregate: water: gypsum = $1: 3.64: 3.64: 0.93: 0.5$ (in weight ratio). The ultimate strength of the microconcrete was $8.94 \mathrm{MPa}$ and the elastic modulus of that was $7.29 \mathrm{GPa}$ consistently with the similitude constant 0.2 in contrast with C40 concrete. Galvanized iron wire was used to replace the reinforcements following the similar rules of internal forces [25].
2.1.3. Plane Design. Considering the architectural space, the physical dimension, and connection plane of the precast elements of high-rise residence in practice, the model was a two-bay, two-span, twelve-story shear wall structure that was regular in plan and elevation. The CIPS and MPCS scaled models were $1800 \mathrm{~mm} \times 1800 \mathrm{~mm}$ in plane and with a constant story height of $600 \mathrm{~mm}$. The distance of span was $1100 \mathrm{~mm}$ and $700 \mathrm{~mm}$ in $X$ direction and $900 \mathrm{~mm}$ and $900 \mathrm{~mm}$ in $Y$ direction. The thickness of the shear wall and coupling beam was $40 \mathrm{~mm}$ and that of the slab was $30 \mathrm{~mm}$. It contained three kinds of coupling beams with different spans: $500 \mathrm{~mm}, 300 \mathrm{~mm}$, and $160 \mathrm{~mm}$ respectively. Figure 1 displays the plane view of the models.

The MPCS model included three kinds of cast-in-place connections binding precast elements, "L" type, "T" type, and "+" type, to form an entirety part in each story and three kinds of precast concrete shear walls (PCSW): PCSW-1, PCSW-2, and PCSW-3. The three connections represented the external PCSW connected in corner, external and internal PCSW connected in side, and internal PCSW connected inside of precast structure. Moreover, the cast-in-pace connections were corresponding to the edge components of shear wall of the CIPS model which were separated from the precast element in the factory and then made with cast-in-place concrete after the precast elements were installed. Namely, the cast-in-pace connections and the PCSW composed the shear wall of CIPS. The design parameters, model materials, and loading program of MPCS were the same as those of CIPS. However, the models had diverse construction techniques. The details reinforcements of the cast-in-place connections or the edge components and PCSW are exhibited in Figure 2.

2.2. Precast and Construction Details. The structural measures of CIPS were complying with provisions of the code [21]. The CIPS model was constructed in the general construction technique including assembling reinforcement, template installation, pouring concrete, and maintenance. However, the precast units are fabricated in factory, transported to the construction site, and lifted by crane and combined together with the cast-in-place concrete later forming the monolithic precast concrete structure in practice. In this project, a compromised construction method was adopted. The model precast concrete shear walls were fabricated in the laboratory. The reinforcements were connected by the following ways. The upper protruding bar extended through the grouted sleeve to connect the next PCSW, and the side one hooked the longitudinal reinforcements in CIP connection and put on additional stirrups later. Between the upper and lower PCSW, the cast-in-place floor replaced the assemblemonolithic concrete composite slab with similar stiffness for convenience. The remaining CIP connection and floor were poured after the PCSW was cured in 48 hours. Therefore, the coupling beam was precast superposed one in MPCS, and that in CIPS was integrity. The model material was microconcrete mixed gypsum with 8.94 MPa. The procedures of MPCS and CIPS are shown in Figure 3. They were cured at normal temperature for 28 days and tested by shake table under earthquake waves. 


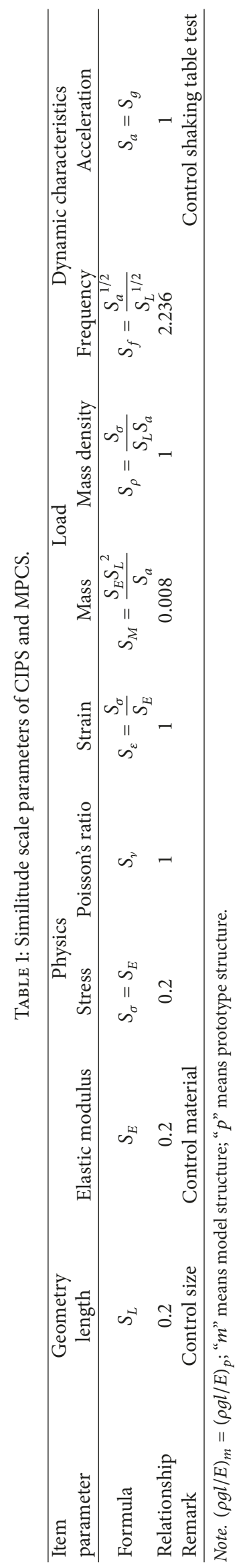




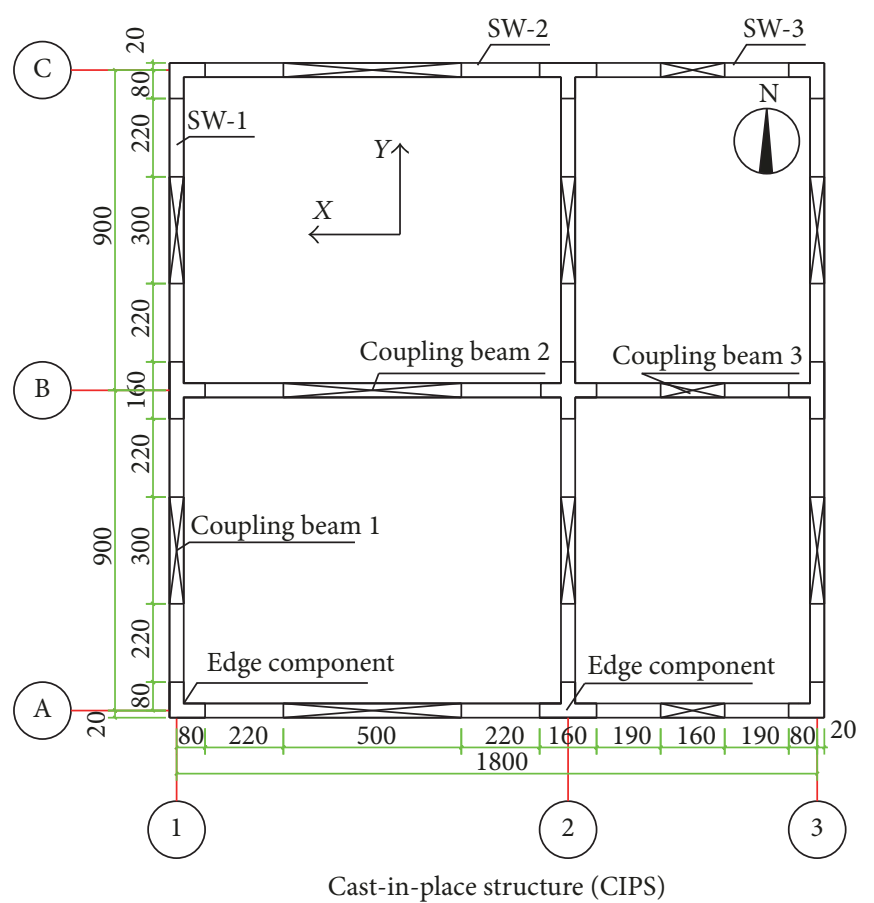

Cast-in-place structure (CIPS)

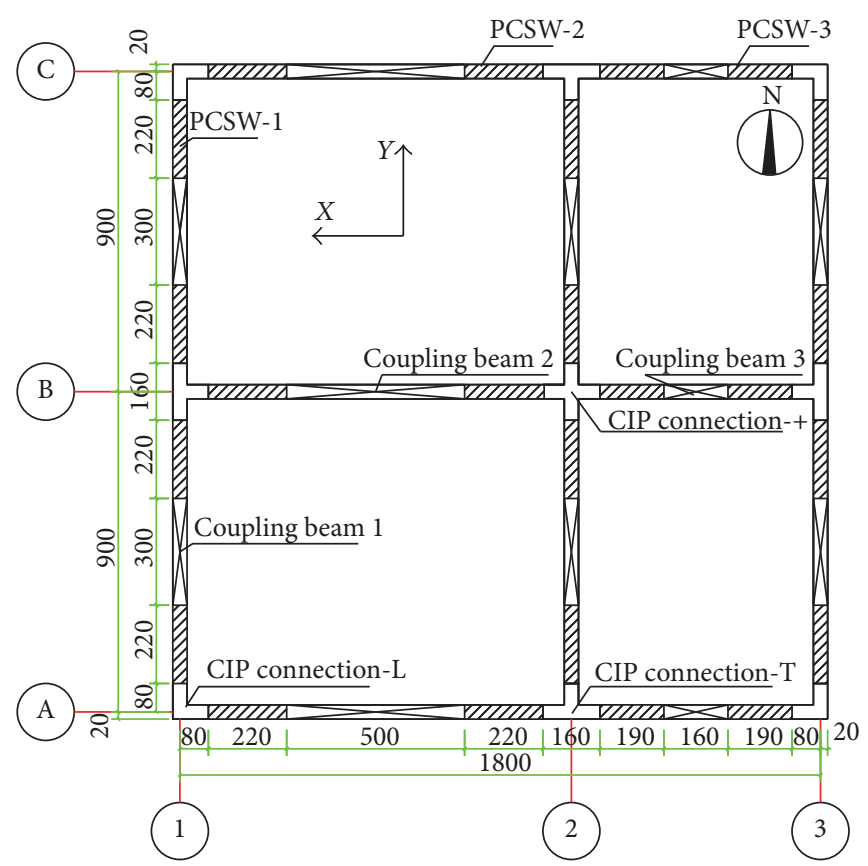

Monolithic precast concrete structure (MPCS)

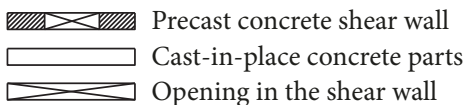

FIgURe 1: Plane view of CIPS and MPCS.

In order to supplement the missing gravity and nonstructural elements, iron blocks were used as the artificial mass and evenly fixed on each floor of the two models about 1.56 tones. The total mass of each model reached 13.6 tones including grade beams and the height of the two models was $7.56 \mathrm{~m}$, which conformed to the capacity limitation of the shaking table system.

2.3. Test Procedure. It is well known that the condition of soil at the site is one of the significant factors in choosing the seismic inputs for shaking table test. The soil layer equivalent cutting wave speed and the thickness of overlay soil layer determine the site classification. The type-II soil site was defined in the Code for Seismic Design of Buildings [21], which was the condition soil of this project. In comparison with seismic design response spectra, Superstition Hills earthquake wave (B-WSM), Kocaeli (Turkey) earthquake wave (DZC), and El Centro earthquake wave (ELW) were selected as the ground excitations and inputted by the mentioned sequence. The waves were chosen from the Pacific Earthquake Engineering Research Center (PEER). The tests were performed with unidirectional and bidirectional earthquake waves with the ratio of PGA $1,0.85$, to evaluate overall seismic performance of CIPS and MPCS. The test program of the shake table test included eight phases and the peak ground acceleration (PGA) is $0.035 \mathrm{~g}, 0.07 \mathrm{~g}, 0.14 \mathrm{~g}, 0.22 \mathrm{~g}, 0.40 \mathrm{~g}$, $0.62 \mathrm{~g}, 0.70 \mathrm{~g}$, and $0.80 \mathrm{~g}$ in each phase, respectively. The PGA of $0.70 \mathrm{~g}$ and $0.80 \mathrm{~g}$ were inputted to observe the nonlinear behavior of them. After each teat phase, the white noise with PGA of $0.035 \mathrm{~g}$ was inputted to detect the dynamitic characteristics of the models.

To monitor the earthquake response of the two models, 32 single-axis accelerometers, including two on the shake table, two on the grade beam, twenty-four on each floor in $X$ and $Y$ directions, and four on the diagonal points in the 12 th floor, were set to record the horizontal acceleration. A total of 12 displacement transducers and 12 velocity vibration sensors were installed to each floor. The arrangement of test instruments is exhibited in Figure 4. Figure 5 displays the models on the shake table.

\section{Failure Pattern and Mechanism}

Cracks and damage to the models were traced along with the increasing PGA. With the PGA of $0.035 \mathrm{~g}$, diagonal microcracks on the coupling beam were merely observed in main direction of CIPS, and those of MPCS were found in $X$ and $Y$ directions of shear wall arranged from 1st to 4th. As the PGA increased from $0.07 \mathrm{~g}$ to $0.22 \mathrm{~g}$, cracks on the CIPS were extended along the corner of coupling beam and some new diagonal microcrack occurred. In the phases, the existing cracks of MPCS penetrated the coupling beam, and meanwhile new microcracks appeared. The diagonal microcracks were the main pattern of the models in this stage.

In the next stage, the models presented different crack patterns. After the PGA of $0.40 \mathrm{~g}$, the cracks of CIPS concentrated rapidly in the end of coupling beams, such as the biggest span-depth ratio one with decreased section 

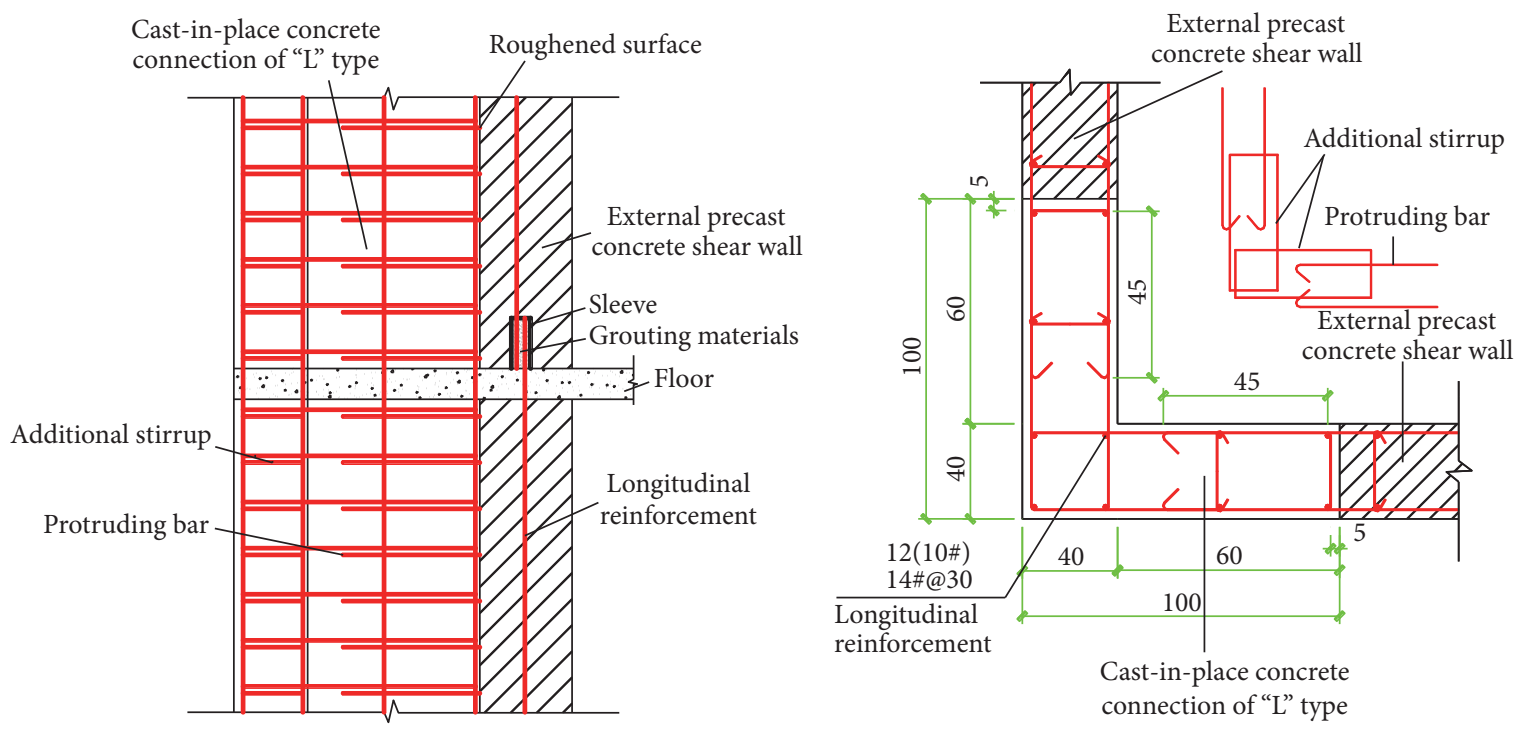

"L" type

Cast-in-place concrete

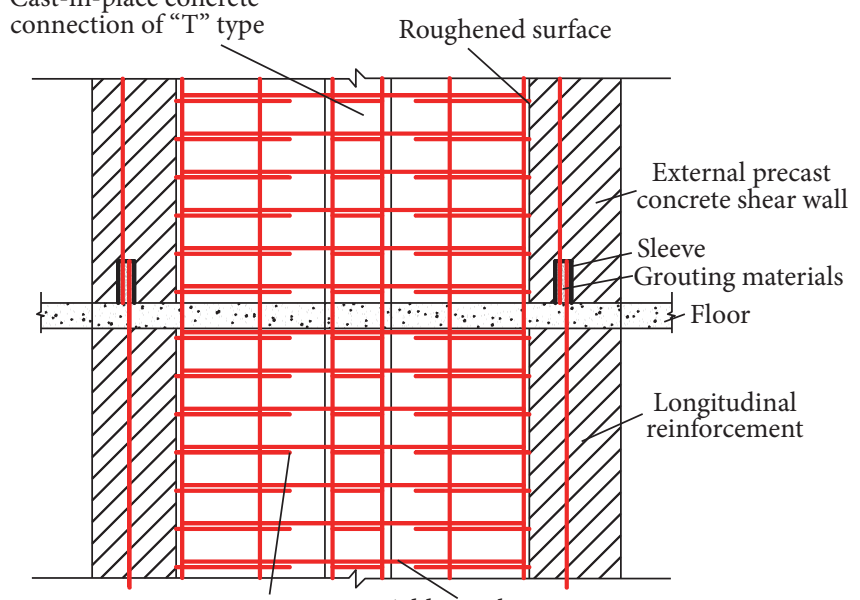

Protruding bar Additional stirrup

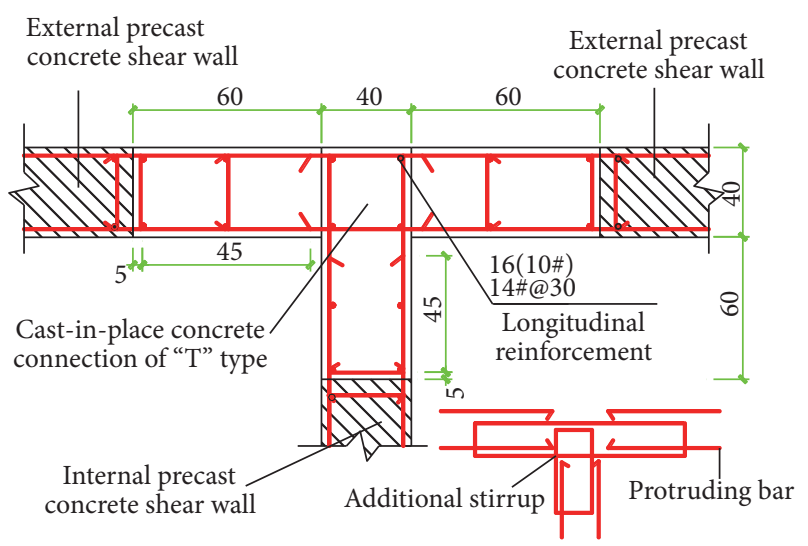

“T” type
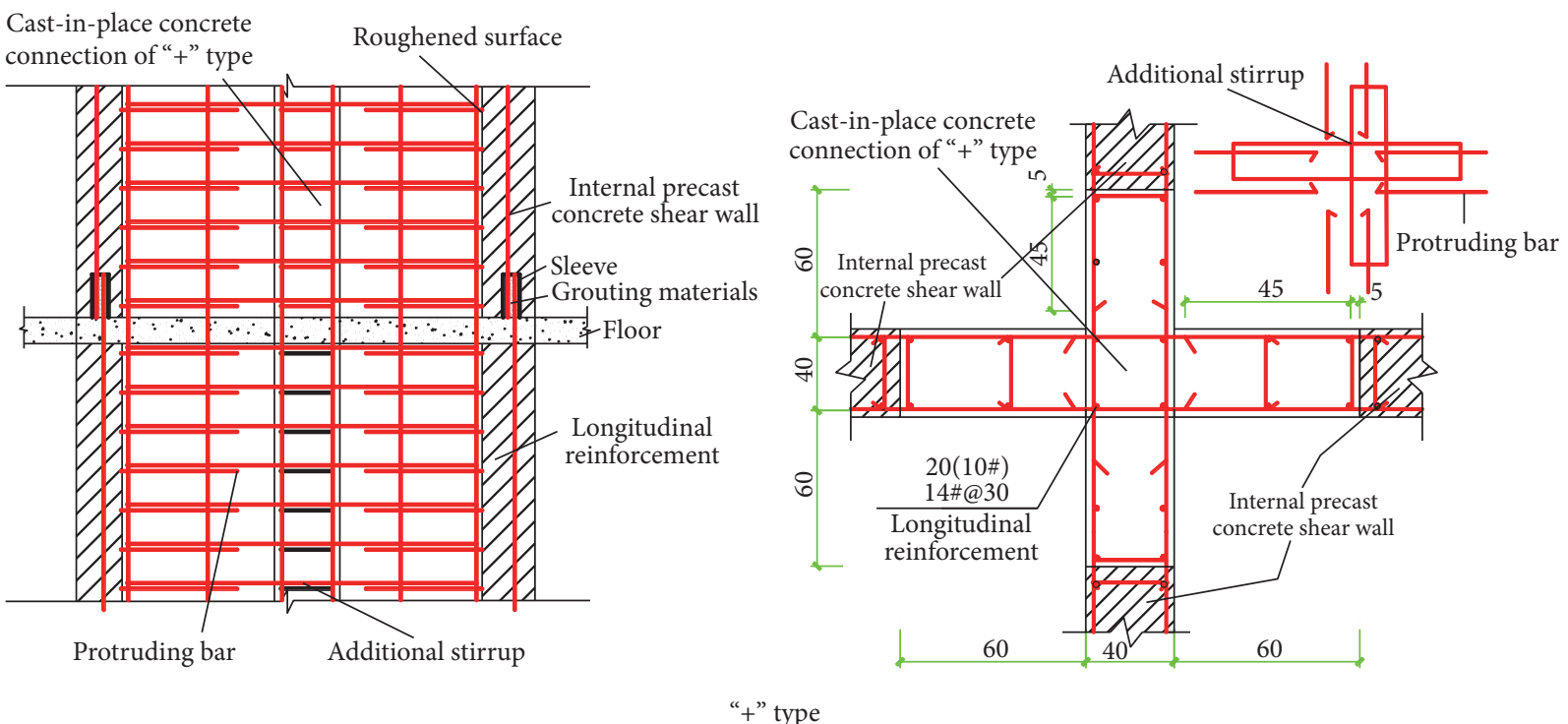

(a) Reinforcement of CIP connections

Figure 2: Continued. 


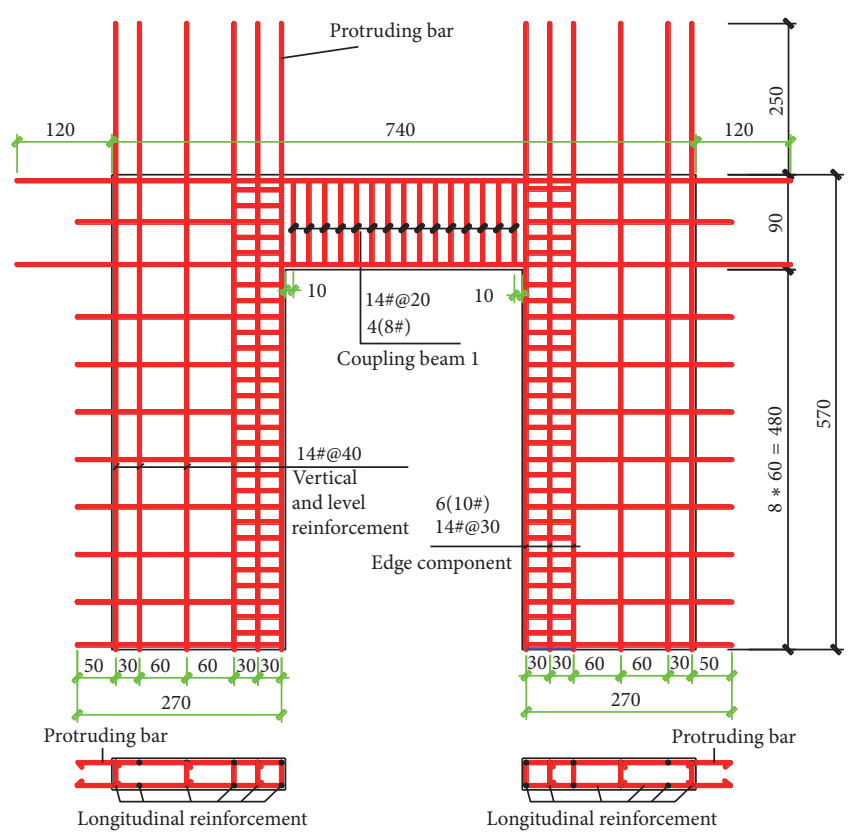

PCSW-1

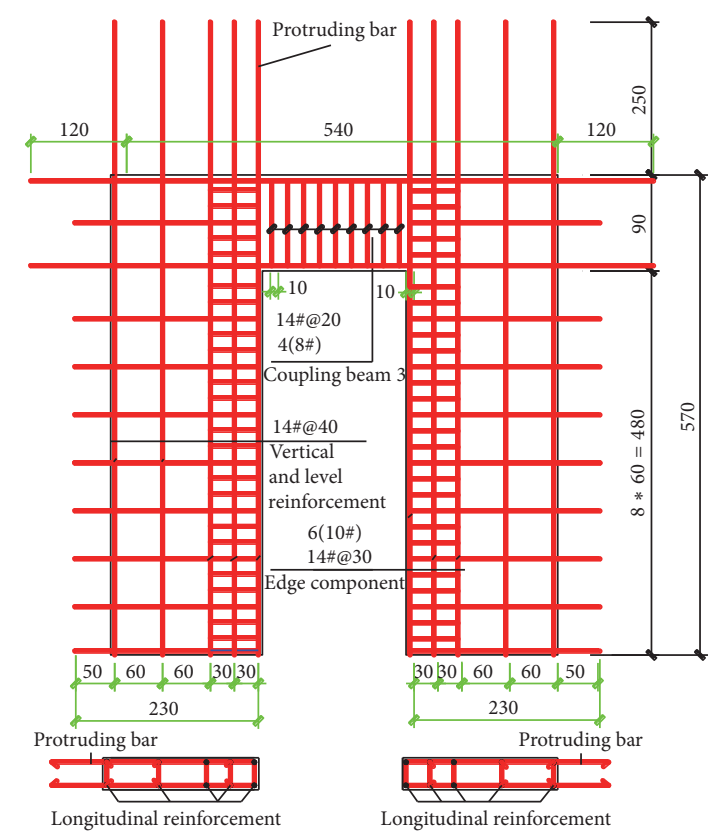

PCSW -3

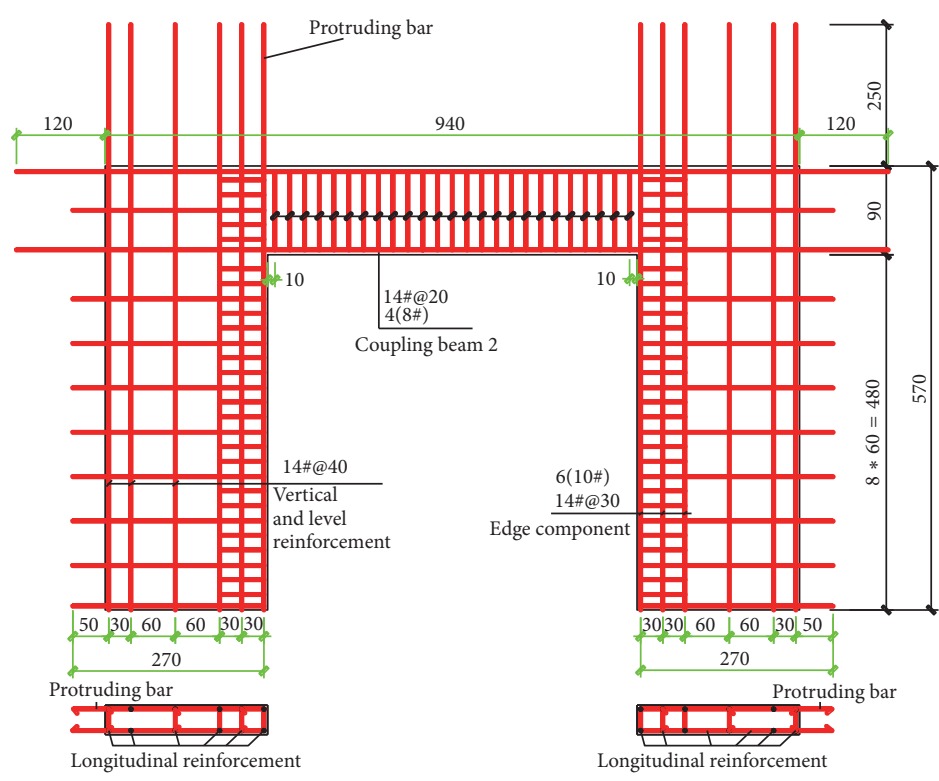

PCSW-2

(b) Reinforcement of PCSW

FIGURE 2: Configuration and reinforcements of the components (unit: $\mathrm{mm}$ ).

for the plastic hinge and the smallest span-depth ratio one with diagonal cracks. On the contrary, diagonal cracks of MPCS extended slowly and the horizontal fracture between the PCSW and the CIP floor as the special form occurred at the same time. With the increasing seismic energy, the new cracks were successively added along the height of the models. The cracks of CIPS were like the diagonal cracks occurring with the PGA of $0.035 \mathrm{~g}$, and those of MPCS were horizontal cracks occurring in horizontal connections. In order to observe the nonlinear behavior of them, the PGA of
$0.80 \mathrm{~g}$ was inputted. In this phase, the vertical cracks along the edge component and the group cracks in the shear wall in 4 th story occurred in CIPS. We considered that the weak story of CIPS was the 4 th story. The horizontal crack extended to the cast-in-place concrete, and the vertical crack appeared in the contact of precast and cast-in-place connection in 2 nd and 3rd stories in MPCS. The overall crack patterns of models are exhibited in Figure 6.

In general, the diagonal cracks were presented in the ending coupling beams of CIPS and MPCS. The phenomenon is 


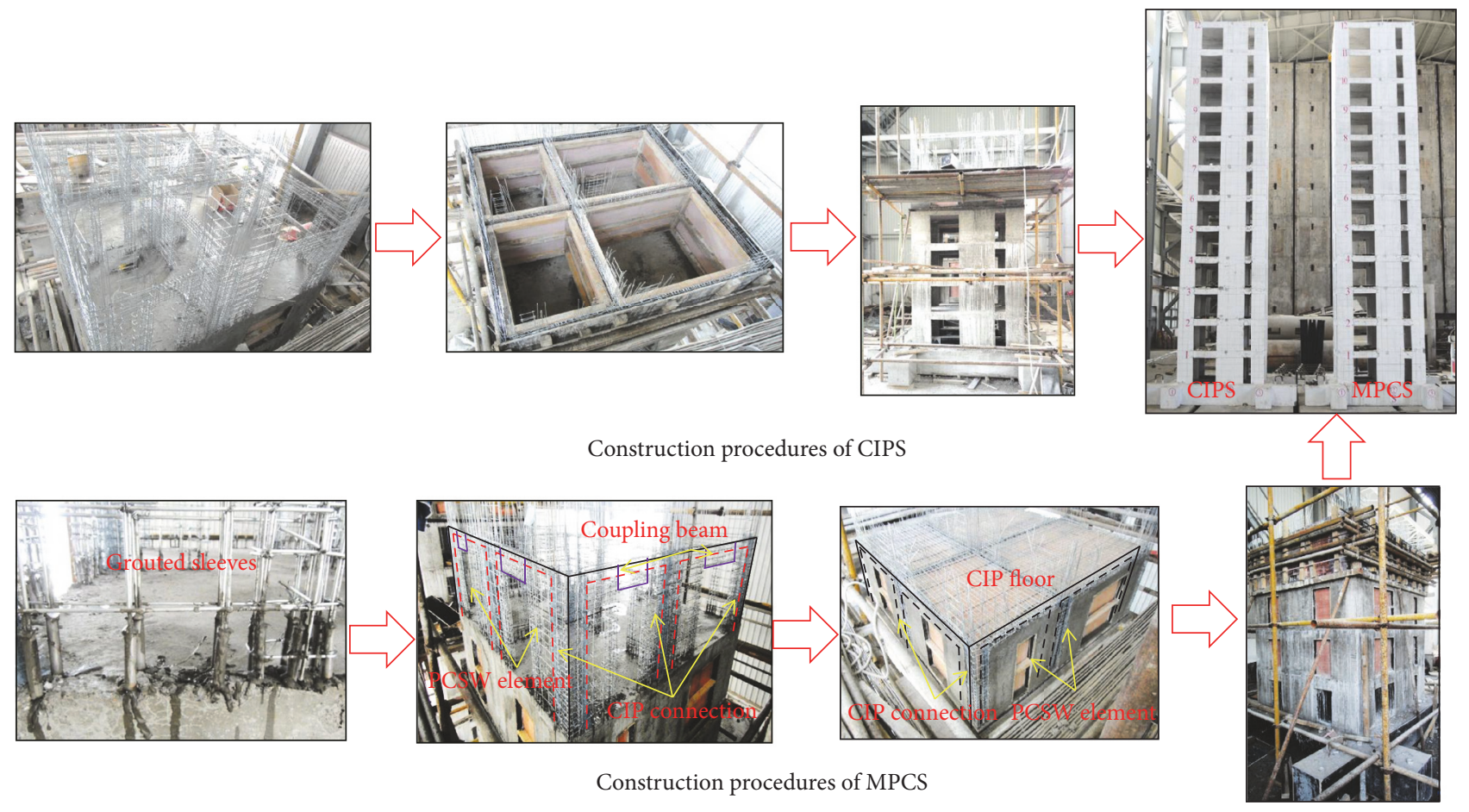

FIGURE 3: Construction procedures of CIPS and MPCS.

TABLE 2: Natural frequency of CIPS and MPCS.

\begin{tabular}{lcccccccr}
\hline & \multicolumn{2}{c}{} & \multicolumn{2}{c}{ Frequency/Hz } & \multicolumn{3}{c}{ Second frequency } \\
PGA/g & \multicolumn{2}{c}{ First frequency } & \multicolumn{2}{c}{ X-direction } & \multicolumn{2}{c}{$Y$-direction } \\
& MPCS & CIPS & MPCS & CIPS & MPCS & CIPS & MPCS & CIPS \\
\hline Initial & 6.19 & 5.13 & 7 & 5.69 & 25.00 & 20.75 & 27.94 & 23.25 \\
$0.035 \mathrm{~g}$ & 4.81 & 5.12 & 5.13 & 5.63 & 20.56 & 20.13 & 22.44 & 23.5 \\
$0.07 \mathrm{~g}$ & 4.80 & 5.12 & 5.06 & 5.5 & 20.06 & 19.88 & 22.00 & 23.25 \\
$0.14 \mathrm{~g}$ & 4.69 & 4.56 & 4.94 & 5.37 & 19.69 & 19.88 & 21.06 & 22.06 \\
$0.22 \mathrm{~g}$ & 4.26 & 4.13 & 4.44 & 4.81 & 18.25 & 18.13 & 19.81 & 20.94 \\
$0.40 \mathrm{~g}$ & 2.79 & 2.81 & 3.75 & 3.75 & 14.19 & 13.56 & 16.25 & 16.56 \\
$0.62 \mathrm{~g}$ & 2.31 & 1.94 & 3.00 & 2.69 & 11.63 & 10.06 & 13.63 & 13.00 \\
$0.80 \mathrm{~g}$ & 1.86 & 1.55 & 2.88 & 2.54 & 9.38 & 9.42 & 13.18 & 12.88 \\
\hline
\end{tabular}

the favored state. They possessed different energy dissipation mechanisms under the intensity earthquake waves. The coupling beam acted as the first line of energy dissipation. While the coupling beam formed a plastic hinge, the shear wall changed to a single-slice wall to dissipate energy as the second line to forbid collapse in CIPS. Besides the coupling beam, the relatively weak connections between the precast elements played the new way to dissipate energy in MPCS, which were horizontal cracks first and then the vertical cracks. Furthermore, they defended the lateral resisting system in some degree.

\section{Earthquake Response Analysis}

4.1. Dynamic Characteristics. The dynamic characteristics of structure include natural frequency, stiffness, damping ratio, and mode shape. They could be deduced from the white noise inputted after each test phase by the transfer function. The first and second natural frequency in $X$ direction and $Y$ direction are shown in Table 2. Also the stiffness could be calculated with the frequency, and it is presented in Figure 7 [28]. Initial frequency of MPCS was bigger than that of CIPS, and the same to the initial stiffness. We assumed that 


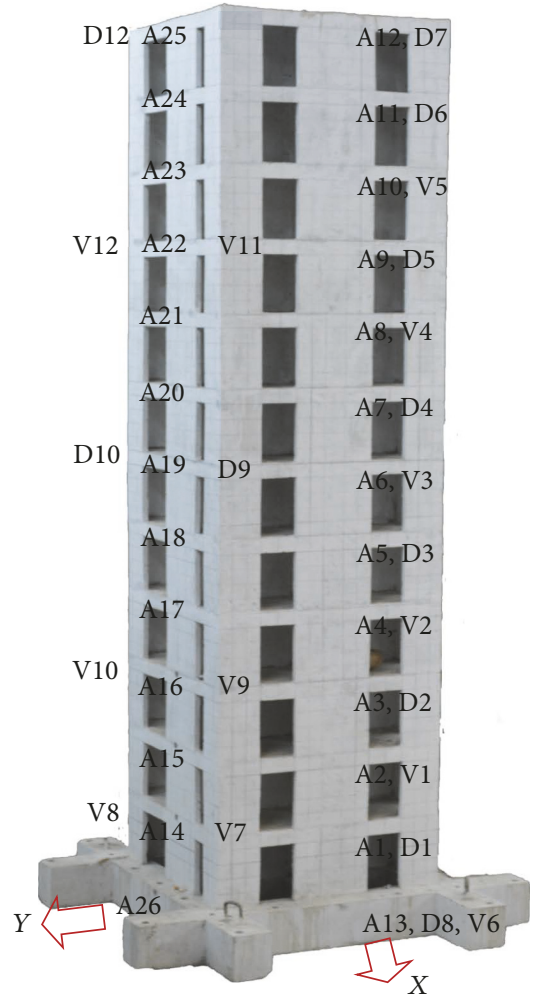

FIGURE 4: Arrangement of accelerometers, displacement transducers, and velocity vibration sensors.
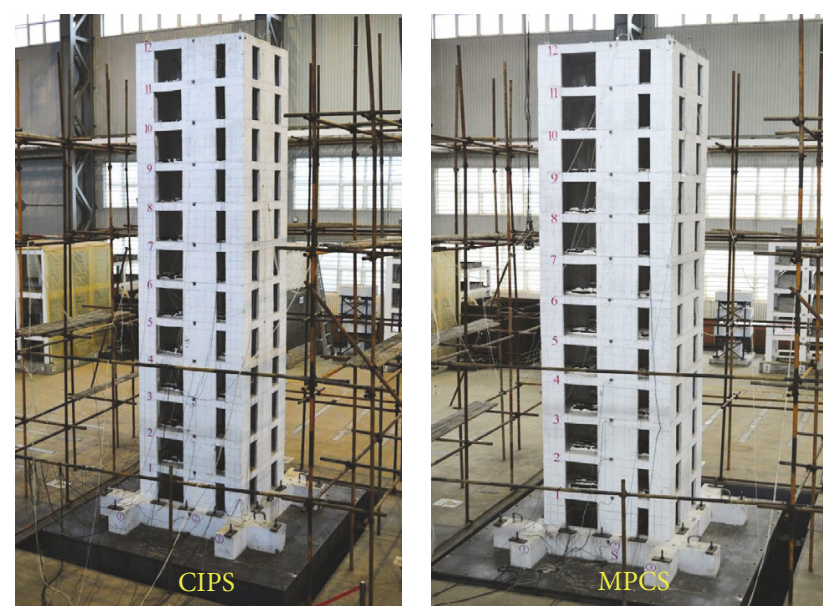

FIgURE 5: General view of CIPS and MPCS.

the adjunction grouted sleeves and the additional stirrups in the connections deduced the phenomenon. As the first earthquake excitation was inputted, the natural frequency of MPCS decreased about 20\%, which could be caused by the shrinkage and microcracks in connections as initial damage [29]. With the increasing energy, the influence of the initial damage was not the main factor. And then the two models with approximately equal frequency presented in failure state. The curves of stiffness degradation of CIPS reduced gradually with the increasing PGA. In contrast with CIPS, that of MPCS

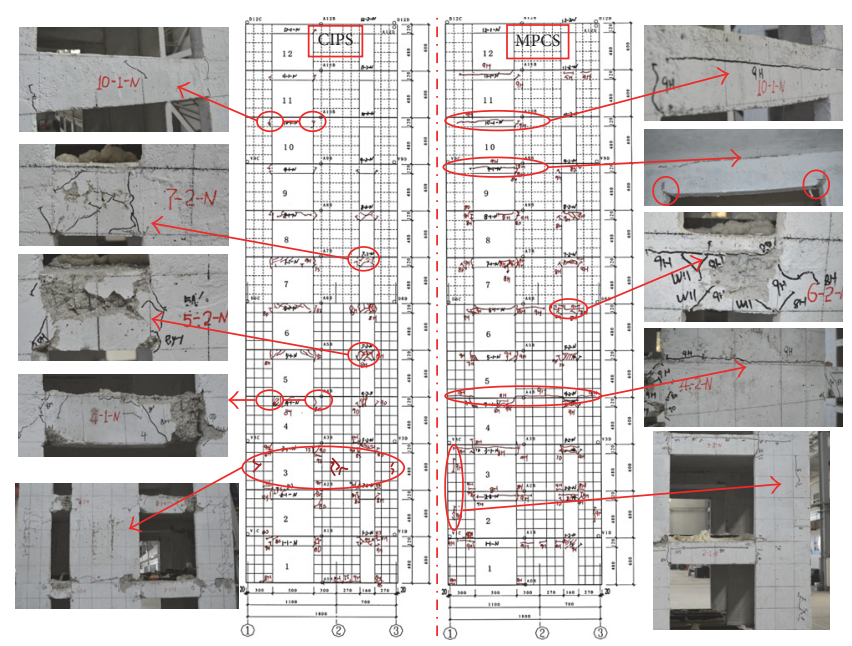

FIGURE 6: Failure patterns of CIPS and MPCS.

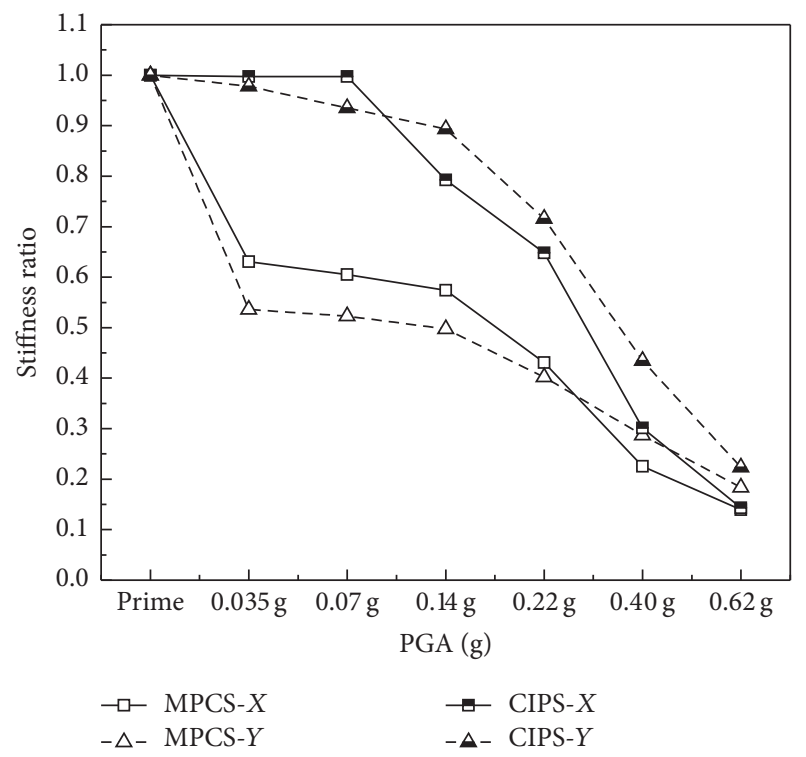

Figure 7: Stiffness ratio versus frequency in $X$ and $Y$ directions.

decreased evidently in the first phase, and then diminished slowly from PGA of $0.035 \mathrm{~g}$ to $0.14 \mathrm{~g}$. Finally, they had similar residual stiffnesses. The diverse tendency might be understood by the mentioned failure pattern.

Damping ratio reflects the dissipation capacity of structure. As is shown in Figure 8, the damping ratio increased gradually following the PGA. In the first phase, it was $4.2 \%$. And then the damping ratio increased slowly before the PGA of $0.40 \mathrm{~g}$, which arranged from $4.2 \%$ to $5.0 \%$. The average damping ratio of each phase changed from $4.2 \%$ to $8.2 \%$ in the loading process, which was in the scope of cast-inplace concrete structure. Nevertheless, the energy dissipation mechanism of CIPS and MPCS was different for the order and distribution of cracks.

The first and second mode shapes of the models are described in Figure 9. In general, the first-order mode shape 


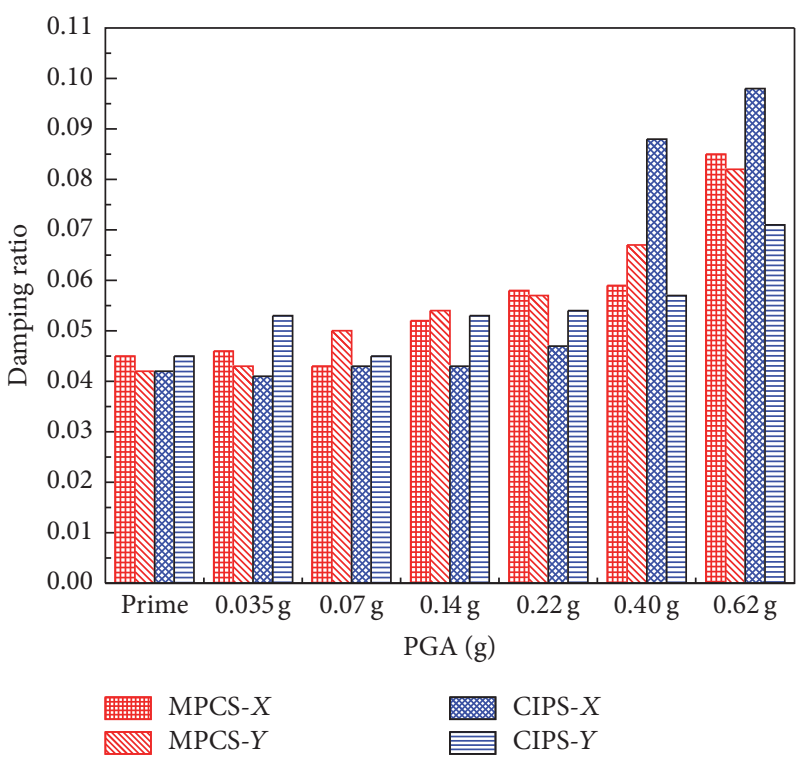

FIGURE 8: Damping ratios of CIPS and MPCS.

exhibited bending deformation characteristics and the lateral stiffness was uniform distribution along the height of the model. The shapes of them were bending to $x$-axis little by little. The phenomenon would be caused by high-order modes. And the trend of that of CIPS was more obvious in the PGA of $0.40 \mathrm{~g}$ and $0.62 \mathrm{~g}$, since the severe damage occurred in the shear wall. The second-order mode shapes of them were similar. And the maximum mode coefficient of second mode shape was in positon of 4 th floor.

4.2. Acceleration Response. The ratio of measured acceleration to the corresponding input peak ground acceleration is called the acceleration amplifying factor. It reflects the dynamic response of structure under earthquake excitations. The acceleration amplifying factors along the height of the models are described in Figure 10(a) under the B-WSM, DZC, and ELW ground motions for different seismic levels. Obviously, that of the two models was gradually increased along the height of the model in each test phase. With the increasing PGA arranged from $0.07 \mathrm{~g}$ to $0.62 \mathrm{~g}$, the whole development trend of that decreased gradually, implying the progressive degradation of structural stiffness. In each test phase, the models presented different dynamic responses under the different earthquake excitations. In elastic stage with the PGA of $0.07 \mathrm{~g}$ and $0.14 \mathrm{~g}$, the CIPS had greater response to B-WSM and ELW than to DZC. The MPCS had uniform response to the three excitations. The earthquake waves with different frequency-spectrum characteristics would lead to this phenomenon. The greatest response of CIPS occurred under the ELW with PGA of $0.22 \mathrm{~g}$, and that of MPCS occurred in the B-WSM with PGA of $0.40 \mathrm{~g}$. The diversities of two models about the acceleration amplifying factors could be caused by the connections between the precast elements. The factors of CIPS and MPCS reduced from 5.46 to 3.19 and from 5.23 to 3.08 in the final test phase, respectively. As shown in Figure 10(b), the distribution feature was more regular under the test phases with PGA from $0.035 \mathrm{~g}$ to $0.14 \mathrm{~g}$. When the two models were subjected to severe damage, the influence of high-order vibration modes increased gradually and the acceleration amplifying factors at some measurement points no longer conformed to the distribution [30].

4.3. Earthquake Action. The seismic force distribution characteristic of structure is very important reference for the aseismic design and application of the MPCS and CIPS. The maximum seismic force of the $i$ th floor is derived as follows:

$$
F_{i \max }=m_{i}\left|\left\{\ddot{x}_{i}(t)+\ddot{x}_{0}(t)\right\}_{\max }\right|,
$$

where $F_{i \max }$ is the maximum seismic force; $m_{i}$ is the lumped mass of the $i$ th floor; $\ddot{x}_{i}(t)$ is the acceleration response of the $i$ th floor relative to the ground at the time of $t$, and $\ddot{x}_{0}(t)$ is the ground acceleration at the time of $t$.

According to (1), the maximum seismic forces of CIPS and MPCS are presented and compared in Figure 11. As illustrated in Figure 11(a), the results of them were presented in linear behavior following the increasing earthquake waves with PGA from $0.035 \mathrm{~g}$ to $0.14 \mathrm{~g}$. The curves were increased progressively along the height of models. They could reflect the actual seismic force distribution in some extent of structure in the elastic stage, and the high-order modes could be ignored in this time. And then the cracks expanded gradually in different ways of the two models, and the influence of highorder modes worked. The models entered into plastic stage with obvious nonlinearity. The maximum seismic forces of the CIPS emerged in the middle of model, such as 5th, 6th, and 8th. Those of MPCS were in 4th, 5th, and 8th. In the plastic stage with PGA from $0.22 \mathrm{~g}$ to $0.62 \mathrm{~g}$, the distribution of seismic forces changed for the high-order modes.

The interstory shear forces were calculated by (1), and they are illustrated along the height of models in Figure 11(b). The interstory shear force was increased gradually with the PGA and decreased along the height of model structure. In elastic stage, the distribution of the interstory shear of CIPS and MPCS showed similar rules like inverted triangle. In plastic stage, the vibration trend was effected by the high-order modes, and interstory shear force was not strictly meeting the distribution pattern.

4.4. Displacement Response. The maximum story displacements of the CIPS and MPCS along the model height obtained from the B-WSM, DZC, and ELW with the PGA from $0.035 \mathrm{~g}$ to $0.62 \mathrm{~g}$ are compared and depicted in Figure 12(a). Since the shear wall structure is the effective lateral resisting system [1], the maximum story displacements of the models were small in 12th story arranged from $1.13 \mathrm{~mm}$ to $7.56 \mathrm{~mm}$ of CIPS and from $1.06 \mathrm{~mm}$ to $6.99 \mathrm{~mm}$ of MPCS in the elastic stage. The stage contained the PGA from $0.035 \mathrm{~g}$ to $0.14 \mathrm{~g}$. With increasing the intensity of earthquake waves, the two models demonstrated different damage phenomena described in the above paragraph. The concentrated damage in shear wall of 4 th story of CIPS caused bigger displacement than that of MPCS. The bigger displacement formed the bigger torsion angle of floor and then brought about the much bigger displacement in upside structure of CIPS. And the 

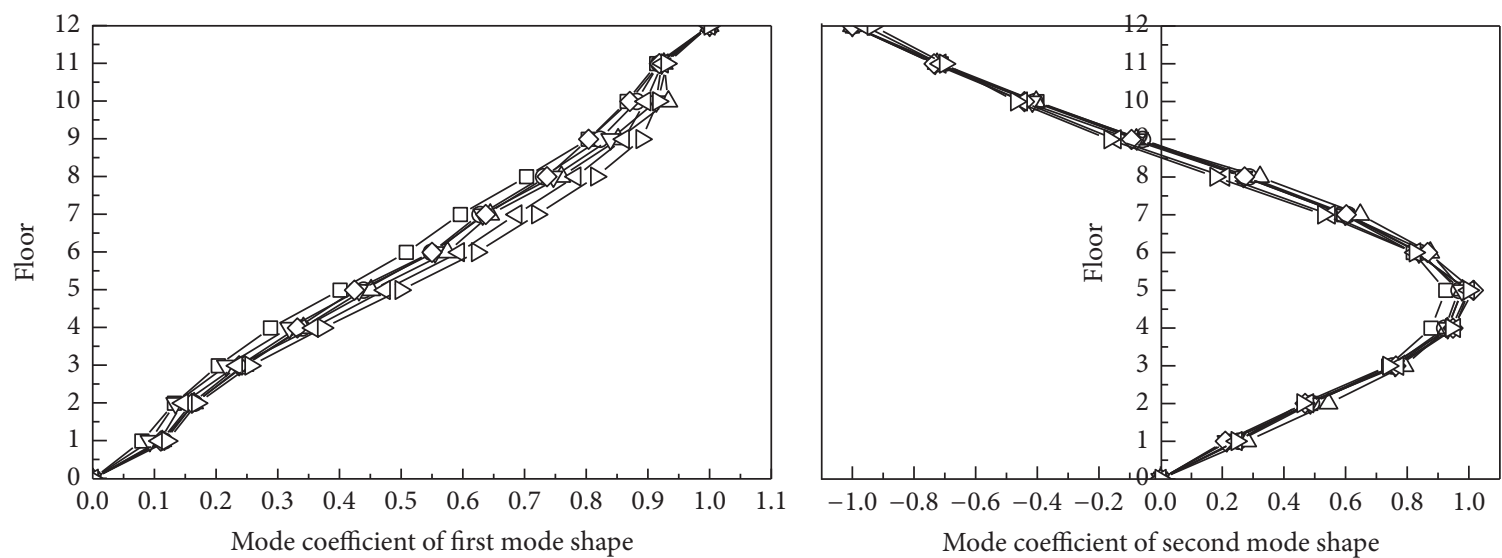
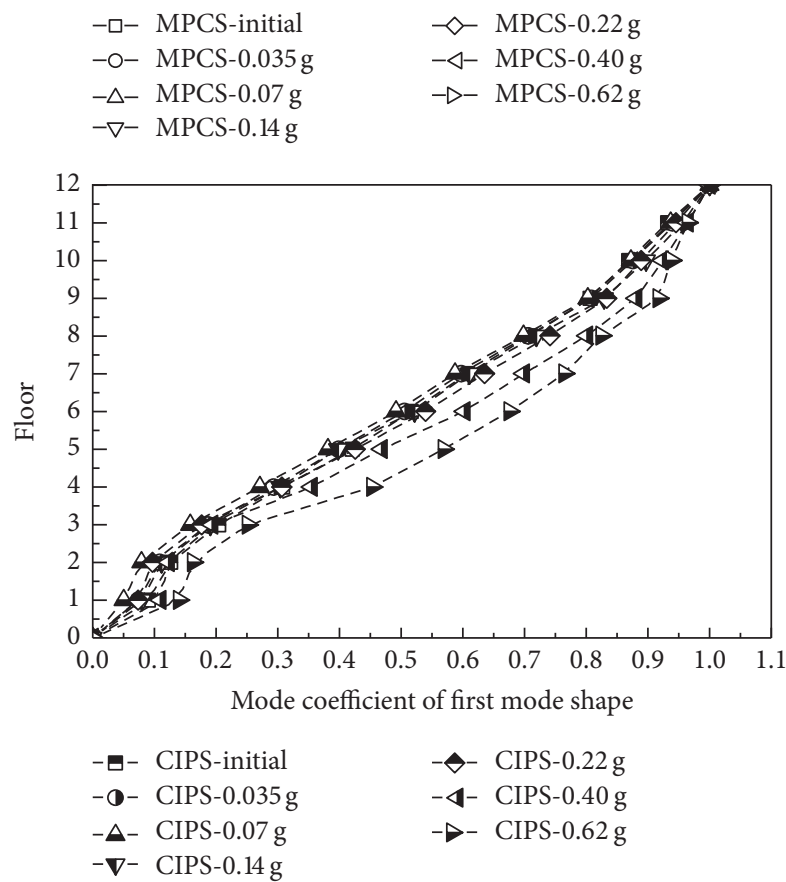
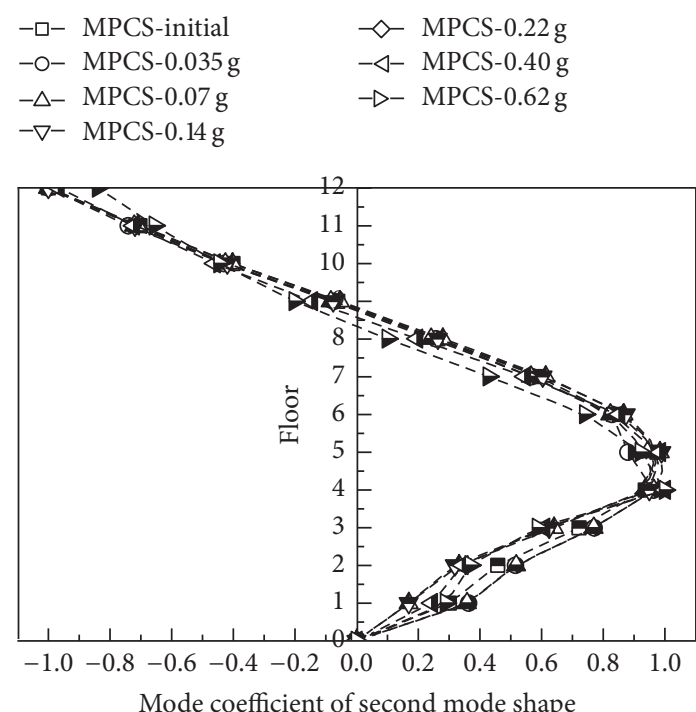

$\begin{array}{ll}-\boldsymbol{-}-\text { CIPS-initial } & -\nabla-\text { CIPS-0.22 g } \\ -\mathbf{-}-\text { CIPS-0.035 g } & -\varangle-\text { CIPS-0.40 g } \\ -\Delta-\text { CIPS-0.07g } & -\diamond-\text { CIPS-0.62 g } \\ -\boldsymbol{\nabla}-\text { CIPS-0.14g } & \end{array}$

FIgUre 9: Mode shapes of CIPS and MPCS.

maximum destructive story drift was in 4th floor. Meanwhile, the two models showed obviously nonlinear behavior with the PGA of $0.40 \mathrm{~g}$ and $0.62 \mathrm{~g}$. The shape of maximum story displacements of them was similar to the first mode shape. The maximum story displacements were $48.67 \mathrm{~mm}$ in CIPS and $41.98 \mathrm{~mm}$ in MPCS.

The maximum interstory drift ratios were calculated and presented in Figure 12(b). The maximum value of story drift of CIPS was $1 / 1005$ in 5th story under the DZC earthquake wave with the PGA of $0.70 \mathrm{~g}$, and that of MPCS was $1 / 1020$ in 5 th story under the same wave. They met the provision about the maximum story drift in elastic stage in area of 8degree seismic fortification intensity in code of GB 500112010 [21]. In the stage from PGA of $0.035 \mathrm{~g}$ to $0.14 \mathrm{~g}$, the story drift increased progressively. The seismic design code asks for the limiting value of plastic interstory drift ratio to forbid collapse. We checked the story drift under the PGA of $0.40 \mathrm{~g}$. The values of CIPS and MPCS were $1 / 121$ and $1 / 127$, which met the limiting value in rare earthquake action of 8degree seismic regions. Under the excitation of PGA of $0.62 \mathrm{~g}$, the values exceeded the limiting value in rare earthquake action of 9-degree seismic regions. And then the more intensive earthquake waves with PGA of $0.80 \mathrm{~g}$ were inputted; the models presented better seismic behavior without collapse.

\section{Conclusion}

A comparative seismic study between CIPS and MPCS was conducted by shaking table test, which contained a 1/5 scaled 12 -story CIPS model and MPCS model. The experimental results of dynamic characteristic, failure pattern and mechanism, and seismic response of the models were discussed and compared with each other to better understand their seismic behavior. Based on the intensive analysis of test results, the following conclusions are derived: 


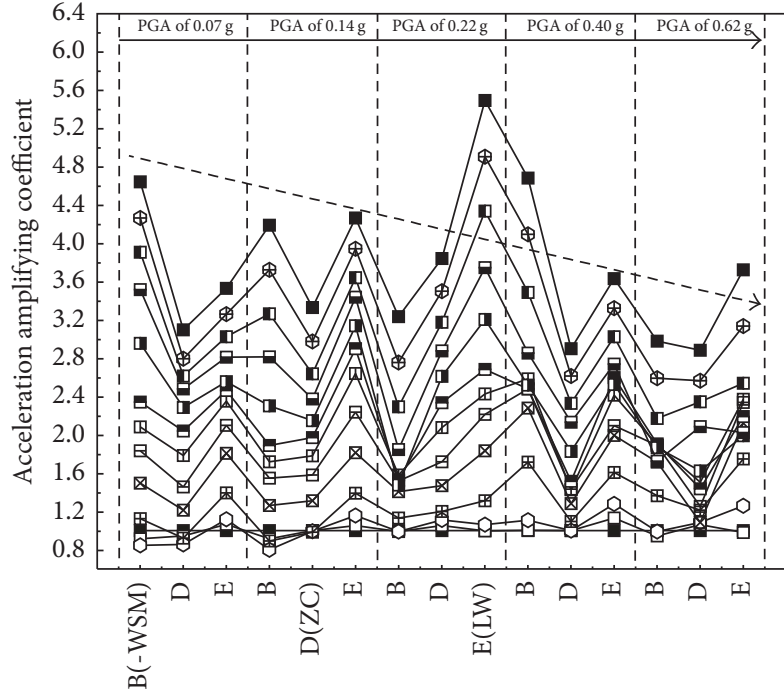

Peak ground acceleration of CIPS (g)

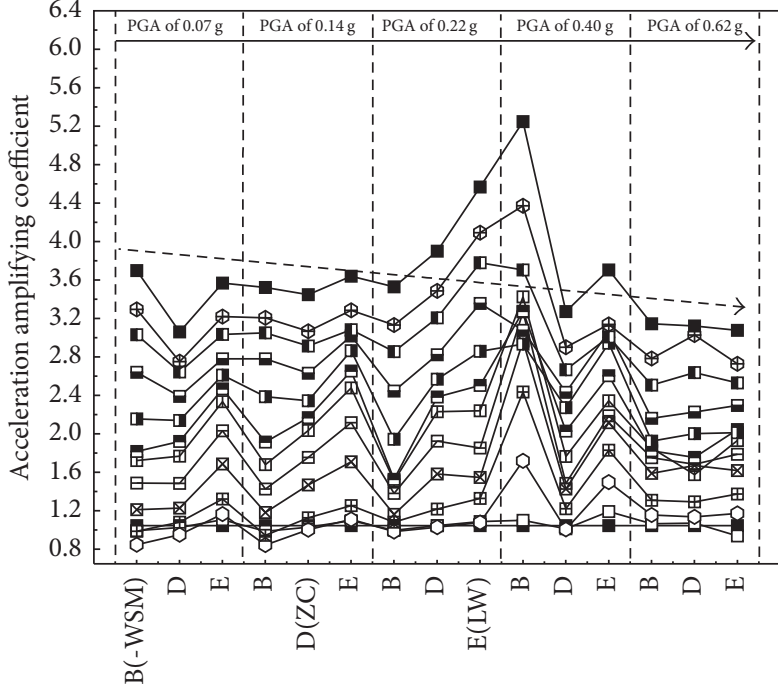

Peak ground acceleration of MPCS (g)
$-0-2$ nd floor

$\rightarrow-1$ st floor

$\rightarrow$ Floor

$\square$ 5th floor

$₫$ 4th floor

$\rightarrow$ 8th floor $\quad \rightarrow$ - 3rd floor

(a) Acceleration amplifying factors changed along the test phases of CIPS and MPCS

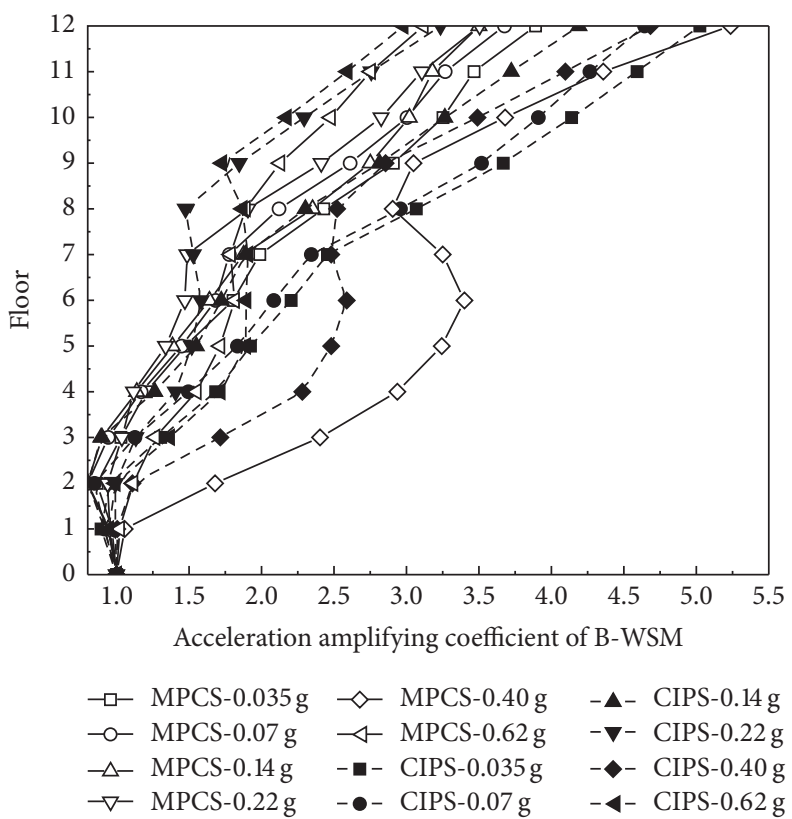

(b) Acceleration amplifying factors of B-WSM wave along the height of two models

FIgURE 10: Acceleration amplifying factors of CIPS and MPCS.

(1) The typical failure pattern of the CIPS was damage concentration in coupling beams in first, and then the cracks emerged in the shear wall in plastic stage. However, besides the concentrated damage in coupling beam, the connections between the precast element and the CIP floor were the weakness, and the vertical crack came after the horizontal crack in plastic stage. The precast element with high qualities did not present cracks in the test.

(2) The initial natural frequency as the initial stiffness of MPCS degraded more obviously than CIPS for the fine cracks in the connections. The damping 


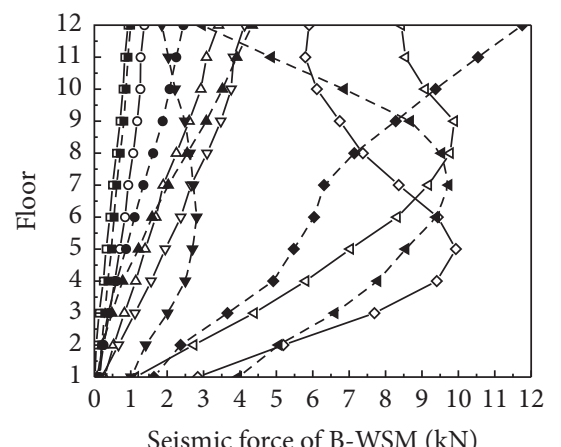

Seismic force of B-WSM (kN)
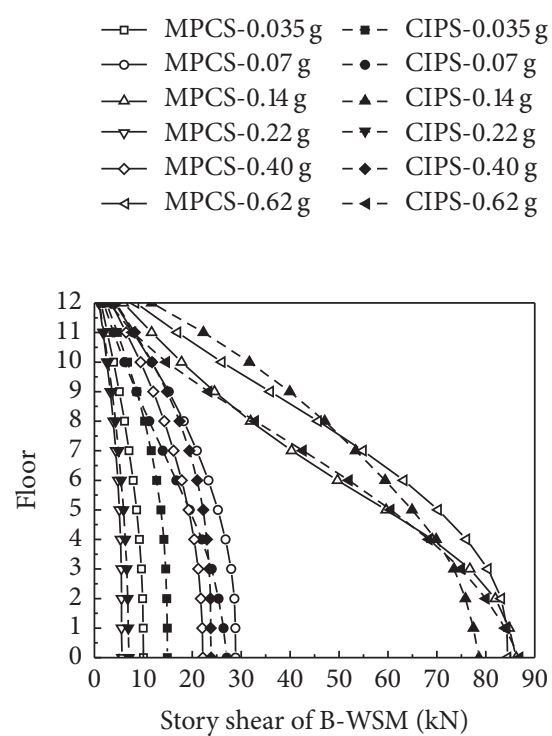

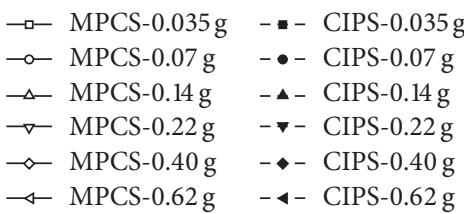

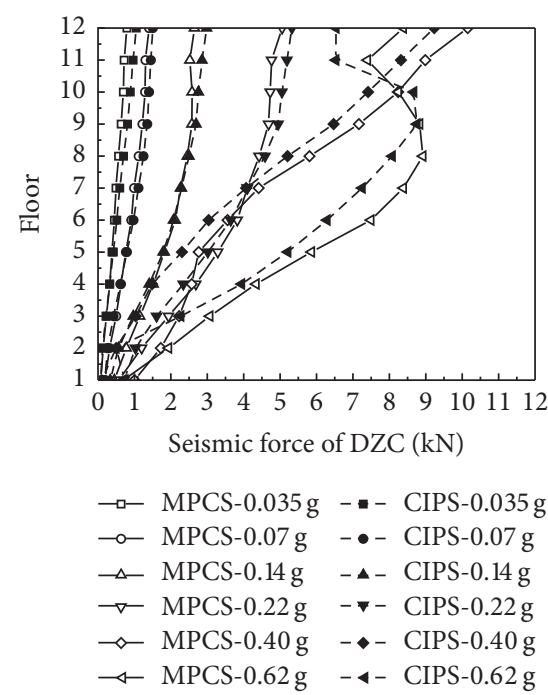

(a) Distribution of seismic forces

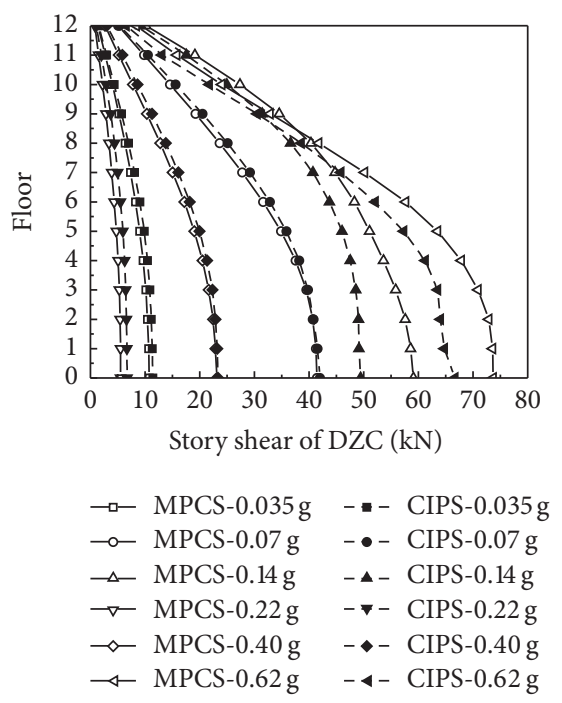

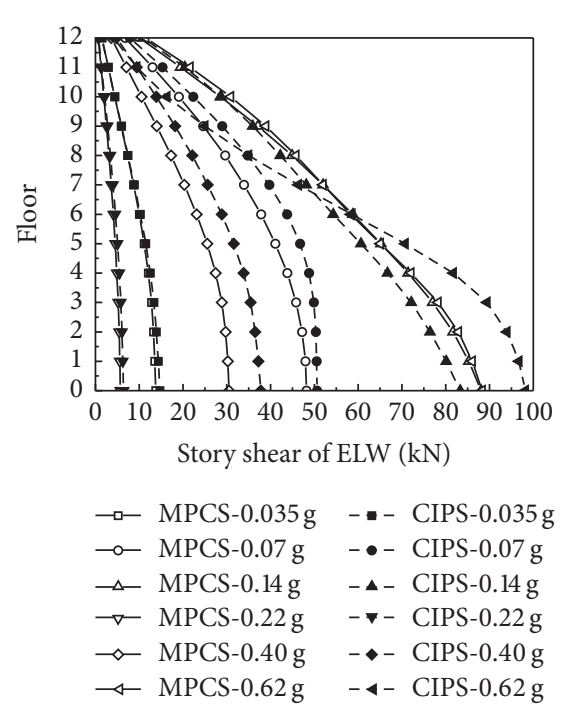
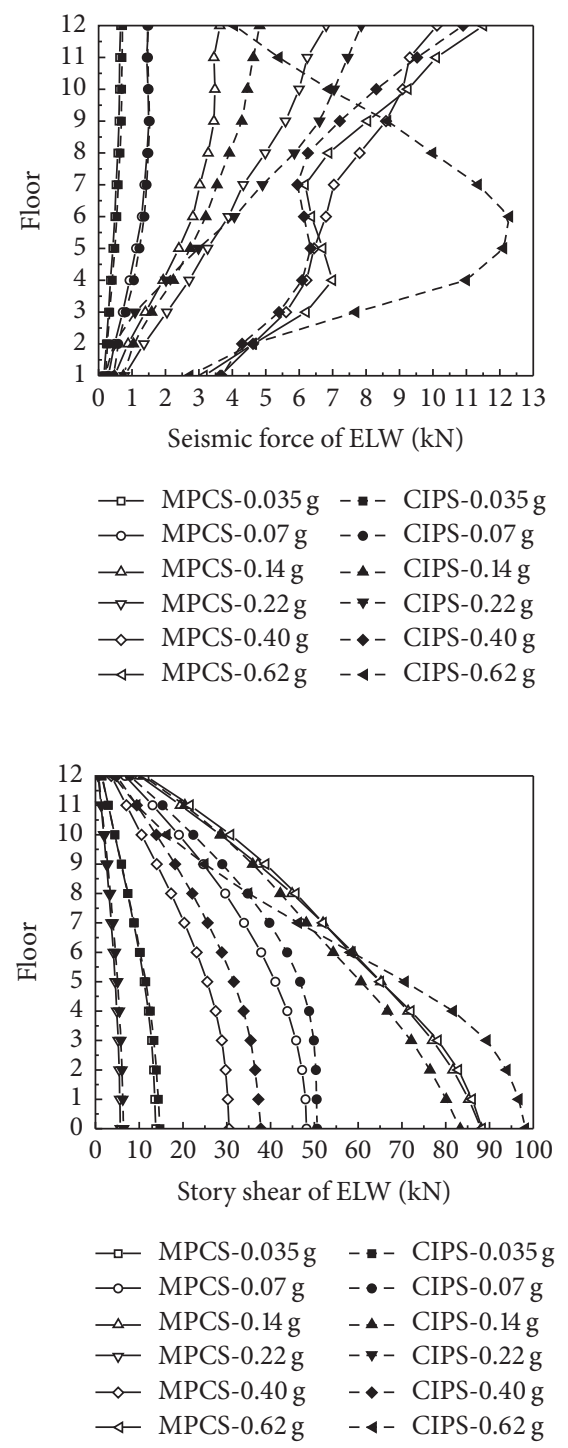

(b) Distribution of story shear

FIGURE 11: Earthquake actions of CIPS and MPCS.

ratio of them had similar parameter, but the way of energy dissipation of them was different. And they had similar mode shapes.

(3) The acceleration amplifying factors of them increased along the height of models and decreased progressively with the increasing PGA. Nevertheless, they had different responses under the different earthquake waves. The maximum acceleration amplifying factor of CIPS was 5.46 under the ELW with PGA of $0.22 \mathrm{~g}$, and that of MPCS was 5.23 under the B-WSM with PGA of $0.40 \mathrm{~g}$.

(4) Distribution of seismic forces of them increased linearly along the height of models and then presented nonlinearity for the influence of high-order modes. The distribution of the interstory shear of CIPS and
MPCS showed similar rules like inverted triangle in elastic stage.

(5) The maximum story displacements of them were almost equal in elastic stage. However, the maximum story displacement of CIPS was greater than that of MPCS in plastic stage, which was caused by the concentrated failure in 4th story of CIPS. The maximum interstory ratio under the seismic waves with PGA of $0.07 \mathrm{~g}$ and $0.40 \mathrm{~g}$ was in accordance with the provision of Chinese code. Under the more intensive earthquake wave of PGA of $0.80 \mathrm{~g}$, the two models had enough capacity to resist collapse.

\section{Conflicts of Interest}

The authors declare that they have no conflicts of interest. 

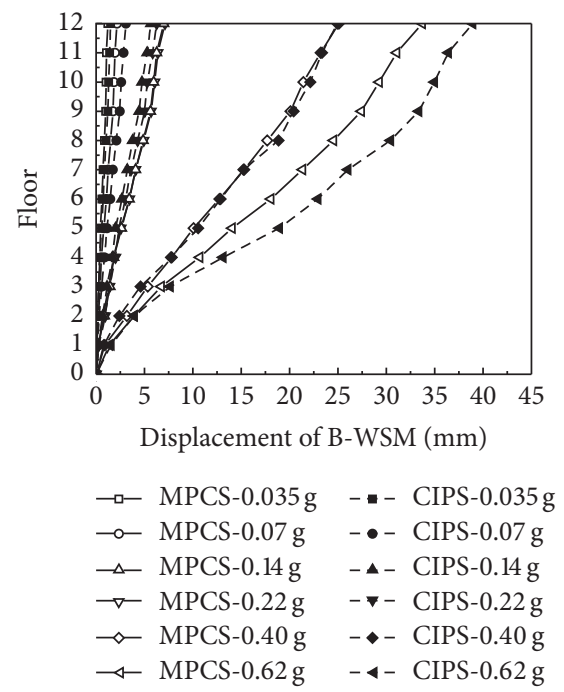

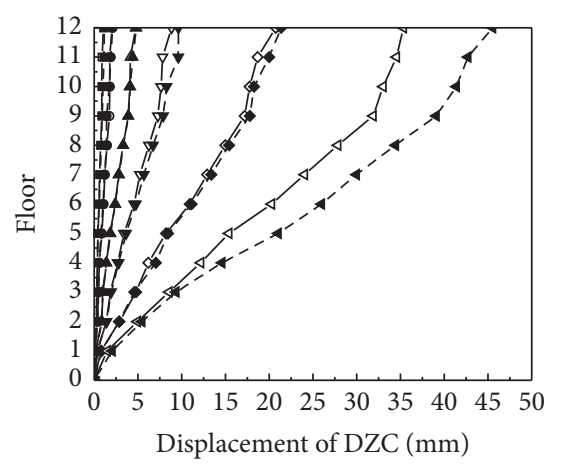

$\rightarrow$ MPCS- $0.035 \mathrm{~g} \quad--\mathrm{-}$ CIPS- $0.035 \mathrm{~g}$

$\multimap$ MPCS-0.07g - $\bullet-$ CIPS- $0.07 \mathrm{~g}$

$\rightarrow$ MPCS- $0.14 \mathrm{~g} \quad-\wedge-$ CIPS- $0.14 \mathrm{~g}$

$\rightarrow$ MPCS $-0.22 \mathrm{~g} \quad-\nabla-$ CIPS- $0.22 \mathrm{~g}$

$\leadsto$ MPCS- $0.40 \mathrm{~g} \quad--$ CIPS- $0.40 \mathrm{~g}$

$\neg$ MPCS-0.62g -4 - CIPS- $0.62 \mathrm{~g}$

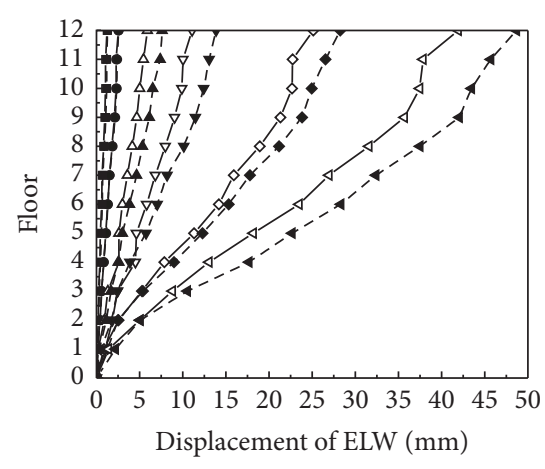

$\rightarrow-$ MPCS- $0.035 \mathrm{~g}--$ CIPS- $0.035 \mathrm{~g}$

$\multimap$ MPCS- $0.07 \mathrm{~g} \quad-\bullet-$ CIPS- $0.07 \mathrm{~g}$

$\rightarrow-$ MPCS- $0.14 \mathrm{~g} \quad-\triangle-$ CIPS- $0.14 \mathrm{~g}$

$\rightarrow$ MPCS- $0.22 \mathrm{~g}-\nabla-$ CIPS- $0.22 \mathrm{~g}$

$\leadsto$ MPCS- $0.40 \mathrm{~g}-$ CIPS- $0.40 \mathrm{~g}$

$\neg$ MPCS- $0.62 \mathrm{~g}-\triangleleft-$ CIPS- $0.62 \mathrm{~g}$

(a) Maximum story displacements of CIPS and MPCS

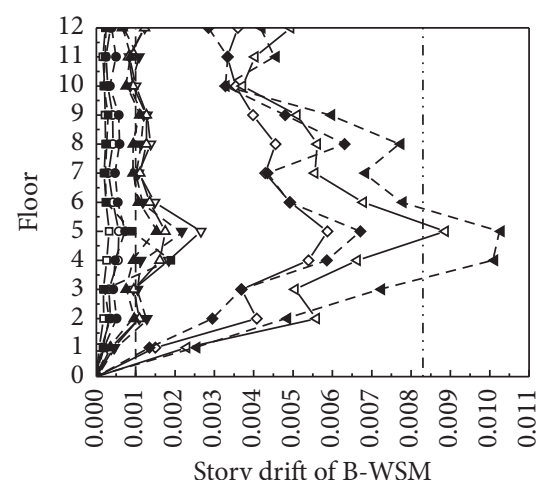

$\rightarrow-$ MPCS- $0.035 \mathrm{~g}-$ CIPS- $0.035 \mathrm{~g}$

$\multimap$ MPCS- $0.07 \mathrm{~g} \quad-\bullet$ CIPS- $0.07 \mathrm{~g}$

$\neg-$ MPCS- $0.14 \mathrm{~g} \quad-\wedge$ - CIPS- $0.14 \mathrm{~g}$

$\rightarrow$ MPCS- $0.22 \mathrm{~g}-\nabla$ - CIPS- $0.22 \mathrm{~g}$

$\leadsto$ MPCS- $0.40 \mathrm{~g} \quad--$ CIPS- $0.40 \mathrm{~g}$

$\checkmark$ MPCS- $0.62 \mathrm{~g} \quad-\triangleleft-$ CIPS- $0.62 \mathrm{~g}$

- - - Elastic limit _... Plastic limit
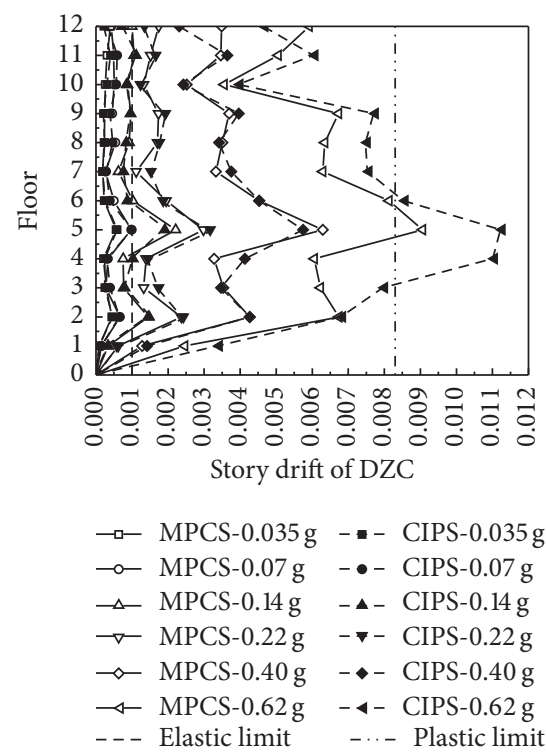

(b) Story drift ratio of CIPS and MPCS

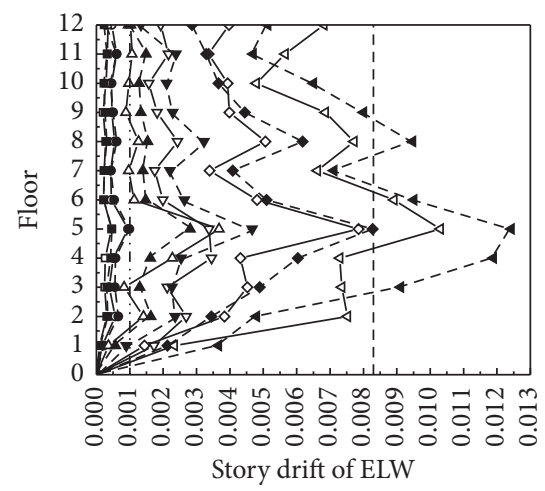

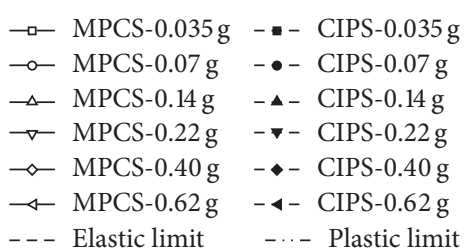

FIGURE 12: Displacement responses of CIPS and MPCS.

\section{Acknowledgments}

This research has been supported by both Innovation Team of Xian University of Architecture and Technology and Shaanxi Province Science and Technology Coordination Innovation Project (nos. 2015KTZDSF03-05-01, 2015KTZDSF03-04, and 2014SZS04-Z01). The support of the National Natural Science Foundation of China (Grants nos. 51408456, 51578444, and 51478381) and Ministry of Education Plan for Yangtze River Scholar and Innovation Team Development (no. IRT13089) is also acknowledged.

\section{References}

[1] R. Park and T. Paulay, Reinforced Concrete Structures, ohn Wiley \& Sons, 1975.
[2] M. Fintel, "Performance of buildings with shear walls in earthquakes of the last thirty years," PCI journal, vol. 40, no. 3, pp. 62-80, 1995.

[3] A. A. Yee, "Splice sleeve for reinforcing bars," US Pat, vol. 3540, 1968.

[4] J. H. Ling, A. B. Abd. Rahman, I. S. Ibrahim, and Z. Abdul Hamid, "Behaviour of grouted pipe splice under incremental tensile load," Construction and Building Materials, vol. 33, no. 8, pp. 90-98, 2012.

[5] M. T. El-Sheikh, R. Sause, S. Pessiki, and L.-W. Lu, "Seismic behavior and design of unbonded post-tensioned precast concrete frames," PCI journal, vol. 44, no. 3, pp. 54-71, 1999.

[6] R. S. Henry, S. Sritharan, and J. M. Ingham, "Unbonded tendon stresses in post-tensioned concrete walls at nominal flexural strength," ACI Structural Journal, vol. 109, no. 2, pp. 171-182, 2012. 
[7] P. Seifi, R. S. Henry, and J. M. Ingham, "Panel connection details in existing New Zealand precast concrete buildings," Bulletin of the New Zealand Society for Earthquake Engineering, vol. 49, no. 2, pp. 190-199, 2016.

[8] K. A. Soudki, S. H. Rizkalla, and R. W. Daikiw, "Horizontal connections for precast concrete shear walls subjected to cyclic deformations part 2: prestressed connections," PCI journal, vol. 40, no. 5, pp. 82-96, 1995.

[9] K. A. Soudki, S. H. Rizkalla, and B. LeBlanc, "Horizontal connections for precast concrete shear walls subjected to cyclic deformations-part 1: mild steel connections," PCI journal, vol. 40, no. 4, pp. 78-96, 1995.

[10] K. A. Soudki, J. S. West, S. H. Rizkalla, and B. Blackett, "Horizontal connections for precast concrete shear wall panels under cyclic shear loading," PCI journal, vol. 41, no. 3, pp. 6480, 1996.

[11] R. Vaghei, F. Hejazi, H. Taheri, M. S. Jaafar, and A. A. Ali, "Evaluate performance of precast concrete wall to wall connection," APCBEE Procedia, vol. 9, pp. 285-290, 2014.

[12] H. Jiang, Z. Chen, J. Zhang, B. Wu, Y. Tian, and W. Liu, "Quasistatic test of precast reinforced concrete shear wall structure," Jianzhu Jiegou Xuebao/Journal of Building Structures, vol. 32, no. 6, pp. 34-40, 2011.

[13] Z. Chen, H. Jiang, J. Zhang, B. Wu, Y. Tian, and W. Liu, "Pseudodynamic substructure test on precast reinforced concrete shear wall structure," Jianzhu Jiegou Xuebao/Journal of Building Structures, vol. 32, no. 6, pp. 41-50, 2011.

[14] J. R. Qian, W. L. Han, Z. Z. Zhao, and H. Qin, "Pseudo-dynamic Substructure Test on a 3-story Full-scale Model of Prefabricated Concrete Shear Wall Structure with Rebars Splicing by Grout Sleeves," Journal of Building Structures, vol. 38, no. 3, pp. 26-38, 2017.

[15] P. Negro, D. A. Bournas, and F. J. Molina, "Pseudodynamic tests on a full-scale 3-storey precast concrete building: Global response," Engineering Structures, vol. 57, pp. 594-608, 2013.

[16] M. Oliva, P. Gavrilovic, and R. W. Clough, "Seismic testing of large panel precast walls: Comparison of pseudostatic and shaking table tests," Earthquake Engineering \& Structural Dynamics, vol. 19, no. 6, pp. 859-875, 1990.

[17] L. H. Lee, W. H. Yi, and S. Y. Seo, "Shaking Table Test of Precast Concrete Wall Structure," in Proceedings of the Eleventh World Conference on Earthquake Engineering.

[18] W. Wang, A. Q. Li et al., "Shaking table test of precast concrete shear wall isolation structure," Journal of Building Structures, vol. 36, no. 6, pp. 35-43, 2015.

[19] EERI, Preliminary Reconnaissance Report, Earthquake Engineering Research Institute, 1994.

[20] EERI, Armenia Earthquake Reconnaissance Report, Earthquake Engineering Research Institute, 1989.

[21] GB 50011-2010, Code for Seismic Design of Buildings, China Architecture and Building Press, Beijing, China, 2010.

[22] JGJ 1-2014, Technical Specification for Precast Concrete Structures, China Architecture \& Building Press, Beijing, China, 2014.

[23] 15J939-1, Example of Architectural Design for Prefabricated Concrete Structures, China Planning Press, Beijing, China, 2015.

[24] E. Buckingham, "On physically similar systems; Illustrations of the use of dimensional equations," Physical Review A: Atomic, Molecular and Optical Physics, vol. 4, no. 4, pp. 345-376, 1914.

[25] Y. Zhou and X. L. Lu, The experimental method and technology of shaking table test about building structure, Science Press, Beijing, China, 2012.
[26] JGJ/T 101-2015, Specification for Seismic Test of Buildings, China Architecture \& Building Press, Beijing, China, 2014.

[27] C. Y. Shen, F. L. Zhou et al., "Experimental research on microconcrete used in dynamic test model," Journal of Guangzhou University (Natural Science Edition), vol. 4, no. 3, pp. 250-253, 2005.

[28] J. Xiao, T. L. Pham, and T. Ding, "Shake table test on seismic response of a precast frame with recycled aggregate concrete," Advances in Structural Engineering, vol. 18, no. 9, pp. 1517-1534, 2015.

[29] S. C. Chakrabarti, G. C. Nayak, and D. K. Paul, "Shear characteristics of cast-in-place vertical joints in story-high precast wall assembly," ACI Structural Journal, vol. 85, no. 1, pp. 30-45, 1988.

[30] C. Wang and J. Xiao, "Study of the seismic response of a recycled aggregate concrete frame structure," Earthquake Engineering and Engineering Vibration, vol. 12, no. 4, pp. 669-680, 2013. 


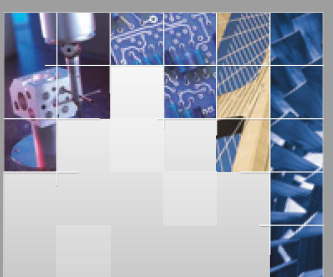

\section{Enfincering}
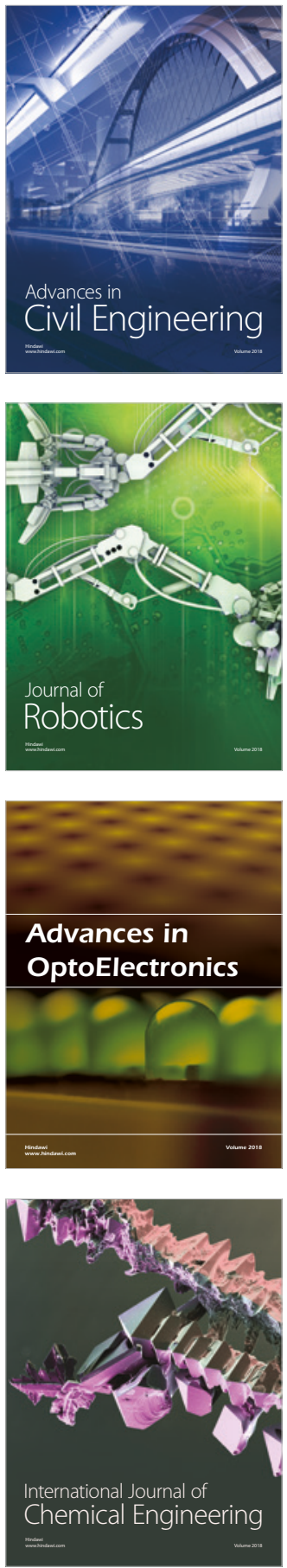

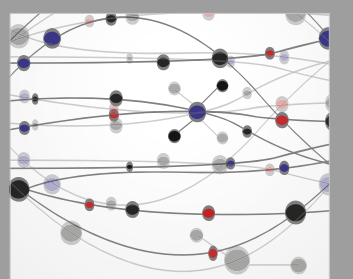

\section{Rotating \\ Machinery}

The Scientific World Journal

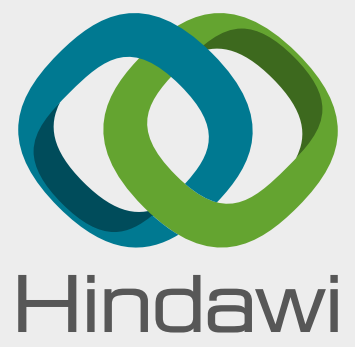

Submit your manuscripts at

www.hindawi.com
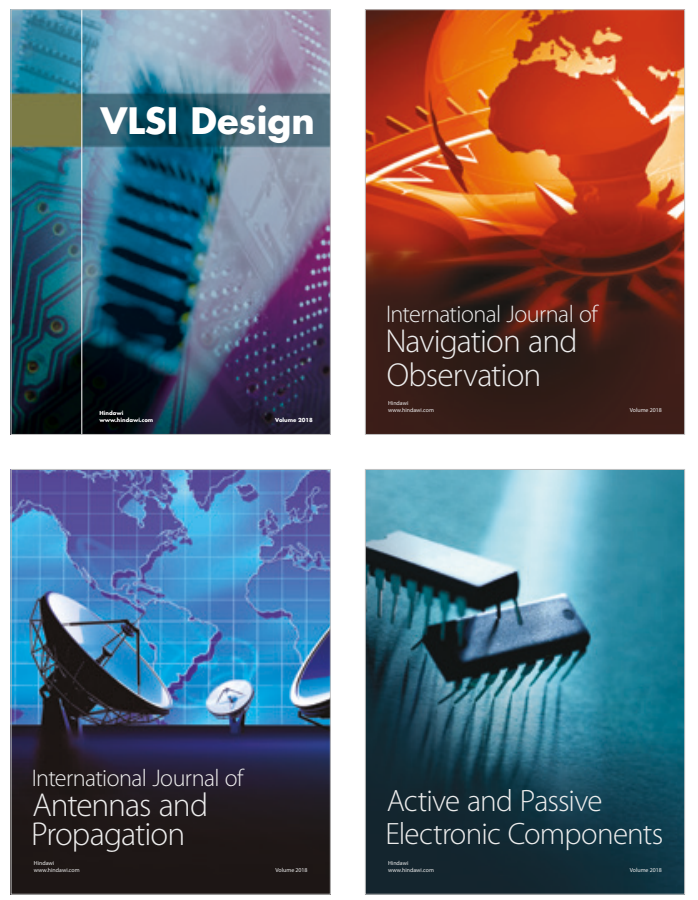
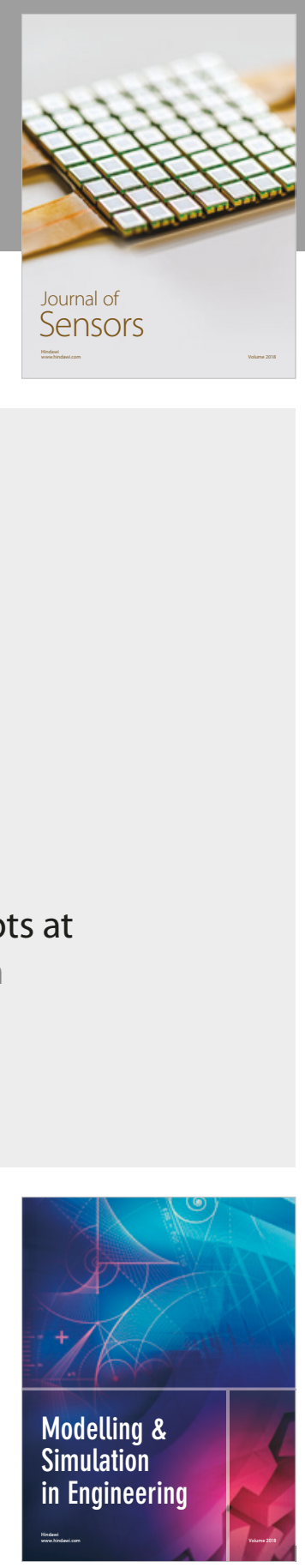

\section{Advances \\ Multimedia}
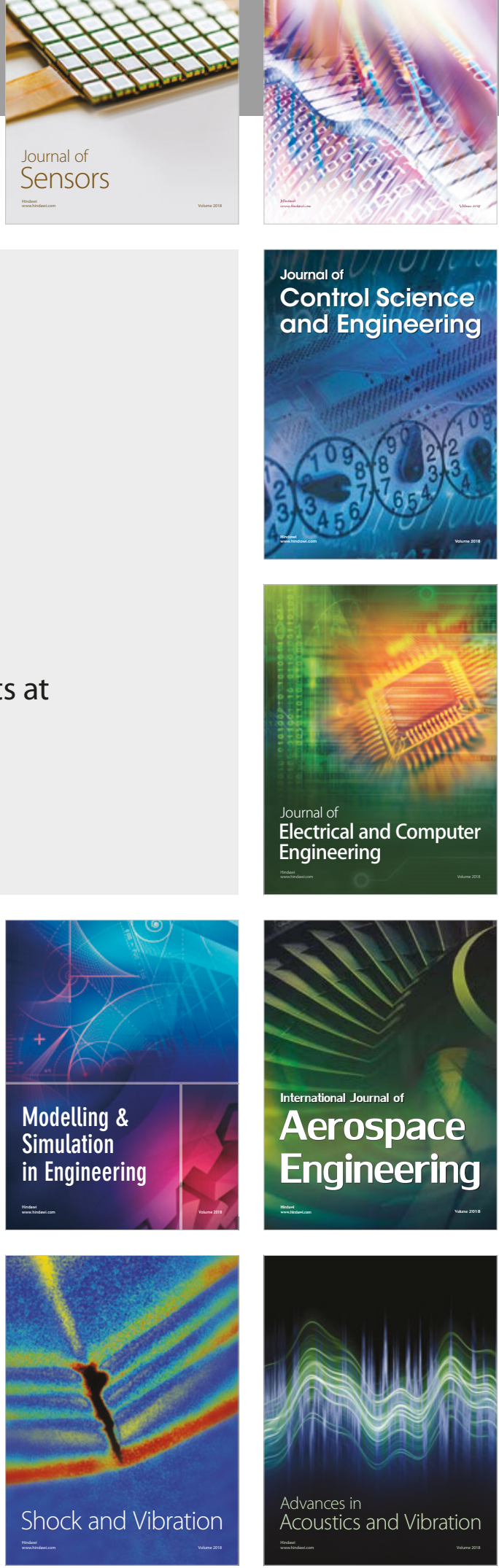